\title{
Continuous video electroencephalogram for herpes simplex encephalitis: a case report and literature review
}

\author{
Wanhui Lin ${ }^{1^{*}+} \mathbb{D}$, Shenggen Chen ${ }^{1+}$, Hanbin Lin ${ }^{1}$, Changyun Liu ${ }^{2}$ and Huapin Huang ${ }^{2,3^{*}}$
}

\begin{abstract}
Background: Electroencephalogram (EEG) is an important tool for the diagnosis of herpes simplex virus encephalitis (HSE). However, the diagnosis of non-convulsive status epilepticus (NCSE) in HSE is challenging without the help of continuous video EEG (CVEEG), and whether EEG is a predictor of outcome remains controversial.

Case presentation: A 63-year-old woman presented with a 5 day history of fever, coma and seizures. Results of $\mathrm{EEG}$, magnetic resonance imaging and polymerase chain reaction (PCR) in cerebrospinal fluid (CSF) were suggestive of herpes simplex encephalitis-1 (HSE-1). Preliminary EEG showed periodic discharges at the prefrontal and temporal lobes, which were particularly synchronized with intermittent lip smacking movements, and the discharges were terminated by diazepam. After 2-week treatment with acyclovir, high-dose hormone pulse therapy and high-dose immunoglobulin therapy, the CSF was improved, but the patient's consciousness became worsen, consistent with the diffuse slow waves in the delta range and low voltage of EEG activity. In the following 1 month, the patient had non-responsiveness to pain and sound as shown by CVEEG with diffuse slow waves. Sometimes paroxysmal very slow waves $(0.5-1 \mathrm{~Hz})$ were synchronized with intermittent paroxysmal eye movements, pupil abnormality, and sweating in the frontal area. After 2 months of treatment, the EEG abnormalities improved to have alpha rhythm.
\end{abstract}

Conclusion: The CVEEG not only helps identify NCSE but can also be used to monitor HSE progression.

Keywords: Herpes simplex virus encephalitis, Video electroencephalogram, Non-convulsive status epilepticus, Periodic lateralized epileptiform discharge, Complications

\section{Background}

Herpes simplex encephalitis (HSE) is the most common cause of sporadic fatal viral encephalitis [1], which has a mortality rate of $\sim 70 \%$ in untreated patients and $19 \%$ in those treated with acyclovir. Moreover, more than $50 \%$ have moderate to severe neuropsychiatric sequelae [2]. The

\footnotetext{
*Correspondence: xiaofeige9903399@126.com; hh-p@163.com

tWanhui Lin and Shenggen Chen contributed equally to this work.

'Intensive Care Unit, Department of Neurology, Fujian Medical University

Union Hospital, Fuzhou 350001, China

${ }^{2}$ Department of Neurology, Fujian Medical University Union Hospital, Fuzhou

350001, China

Full list of author information is available at the end of the article
}

complications of HSE can involve both peripheral and central nervous systems. They include pneumonia and hepatitis, which are commonly seen, and rhabdomyolysis, which is rare in HSE. Recently, with the help of video electroencephalogram (VEEG), non-convulsive status epilepticus (NCSE) can be diagnosed in encephalitis but its diagnosis is often missed in HSE [3]. EEG abnormality is common in HSE. In fact, EEG has been applied in the diagnosis of HSE in as early as 1970 [4-6]. In 1988, Lai CW et al. analyzed the role of EEG in HSE diagnosis [7]. They considered that EEG is more sensitive than other approaches such as computed tomography (CT) and

(c) The Author(s). 2020 Open Access This article is licensed under a Creative Commons Attribution 4.0 International License, which permits use, sharing, adaptation, distribution and reproduction in any medium or format, as long as you give appropriate credit to the original author(s) and the source, provide a link to the Creative Commons licence, and indicate if changes were made. The images or other third party material in this article are included in the article's Creative Commons licence, unless indicated otherwise in a credit line to the material. If material is not included in the article's Creative Commons licence and your intended use is not permitted by statutory regulation or exceeds the permitted use, you will need to obtain permission directly from the copyright holder. To view a copy of this licence, visit http://creativecommons.org/licenses/by/4.0/. 

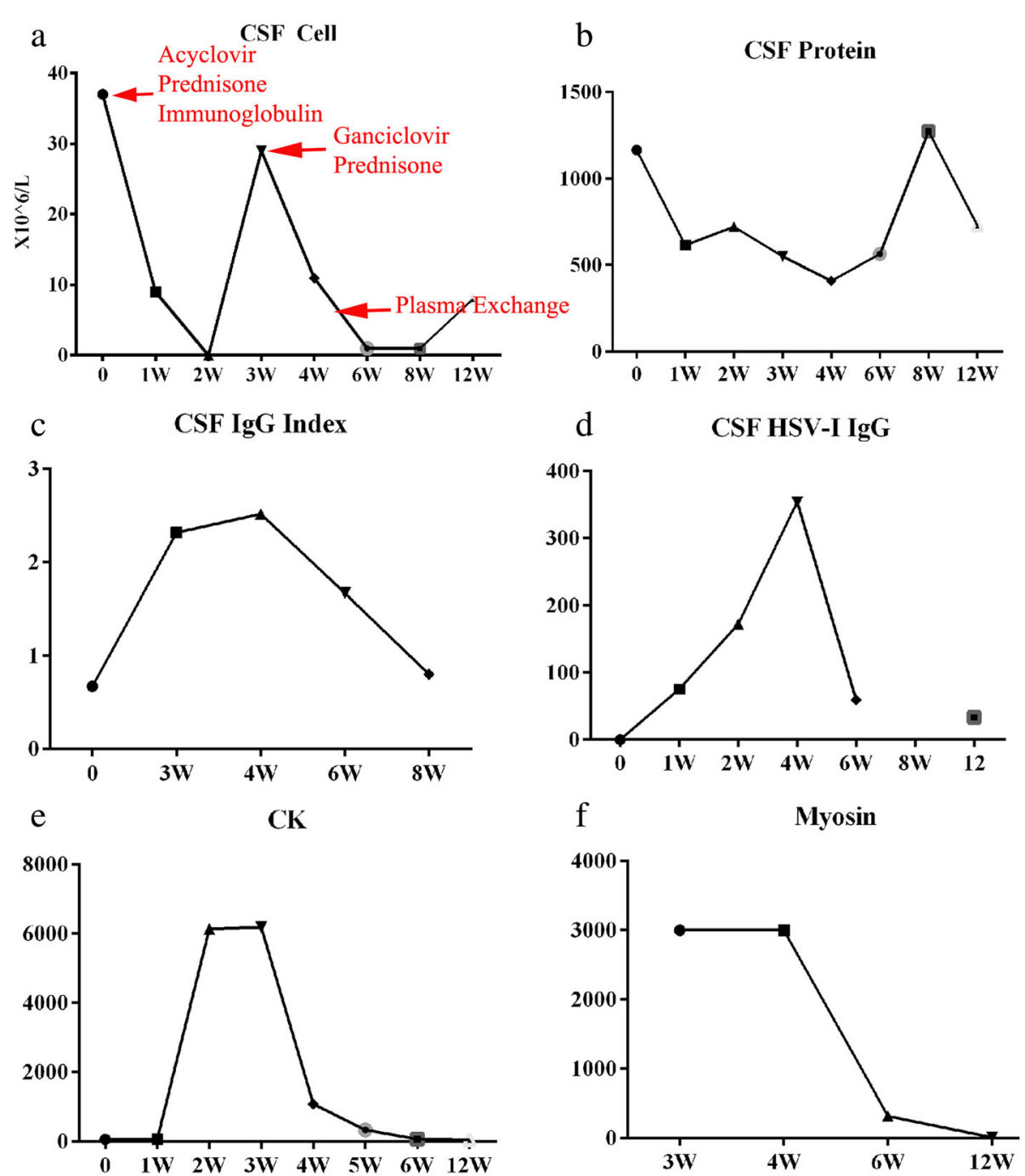

Fig. 1 Dynamic alterations of CSF and blood biochemical indexes during treatment. a On the first day of admission, CSF cells were increased. After two weeks of treatment with acyclovir, hormone shock therapy and immunoglobulin shock therapy, the cell count was decreased to normal level. After 3 weeks of treatment, the cell count increased again. After repeated treatment with prednisone and ganciclovir, it gradually decreased to normal level. $\mathbf{b}$ On the first day of admission, the CSF protein content was increased, and then decreased slowly after treatment. c On the first day of admission, the CSF IgG index was increased progressively, peaked at 4 weeks after admission, and decreased gradually after treatment. $\mathbf{d}$ On the first day of admission, CSF HSV-1 lgG was increased progressively, peaked at 4 weeks after admission, and decreased gradually after treatment. e The level of blood CK increased 2 weeks after admission, was maintained at a high level in the following 1 week, and decreased to normal level in the following 2 weeks. $\mathbf{f}$ The level of urine myosin increased obviously 2 weeks after admission, was maintained at a high level in the following 1 week and decreased to normal level in the following 2 weeks

cerebrospinal fluid (CSF) analysis. A recent study in 379 HSE patients has reported the presence of abnormal EEG activity in $91.0 \%$ of them [8]. The patterns of EEG are diverse rather than specific, commonly including lateralized periodic discharges (LPDs), slow waves, sharp waves, focal seizures, and generalized seizures in the acute period [4-7]. However, how do the patterns of EEG change with the progression of disease? Are these patterns related to the outcome of HSE? How to recognize NCSE with the help of VEEG? To address these questions, we report a case of HSE with serious complications (including rhabdomyolysis) and the use of continuous VEEG (CVEEG) to monitor the progression of HSE, and review the EEG patterns in HSE. We believe that CVEEG is a useful tool to detect NCSE, predict the outcome and monitor the progression of HSE.

\section{Case presentation}

A 63-year-old Chinese female was presented to a local hospital for acute fever $\left(39^{\circ} \mathrm{C}\right)$ and progressive disturbances of consciousness. She had no hypertension/diabetes or other chronic diseases. She was given antipyretic medication (unknown) earlier in clinic. However, her condition 
became worse with progressive disturbances of consciousness. From 5 days before admission, she began to have slurred speech, bizarre behavior and intermittent lip smacking. Her mental status declined further and developed into a state of unconsciousness. She was then transferred to the neurological intensive care unit. Upon arrival, she had no responsiveness to verbal and tactile stimuli, but showed mild withdrawal response to severe pain. She also had intermittent lip smacking movements, during which VEEG showed quasi-periodic discharges at the prefrontal and temporal lobes especially in the left hemisphere, suggesting focal seizure activity. Lumbar puncture was performed on the day of admission and every one or two weeks. The CSF had a pressure of $240 \mathrm{mmH}_{2} \mathrm{O}$ and showed a moderate increase of cells $\left(37 \times 10^{6} / \mathrm{L}\right.$, monocytes accounting for $70 \%$ ) and a significant increase of protein content $(1.154 \mathrm{~g} / \mathrm{L})$, but was negative for herpes simplex virus (HSV)-1/2 IgM (Fig. 1). A meningitis/encephalitis panel by PCR in CSF revealed the presence of HSV-1 $\left(2 \times 10^{4}\right.$ copies) in CSF. CT scanning showed low- density lesions at the bilateral straight gyrus and left hippocampus. Brain magnetic resonance imaging (MRI) with contrast demonstrated increased cortical signal intensities in the bilateral frontal lobes and the bilateral temporal lobes (particularly in the left side), with associated diffusion restriction, indicating cytotoxic edema and enhancement of lesions and meninges, which were highly suggestive of HSE (Fig. 2). CVEEG showed diffuse slowing in the theta and delta ranges and periodic discharges (once per 2-3 s) in correlation with the patient's rhythmic lip smacking movements, which were terminated by diazepam (Fig. 3). The patient was considered as NCSE. Sodium valproate did not fully control the seizures, then levetiracetam was added. A combined intravenous acyclovir, high-dose hormone pulse therapy (prednisone $0.8 \mathrm{qdX} 3 ; 0.5 \mathrm{qdX} 3 ; 0.24$ qdX7) and high-dose immunoglobulin therapy $(0.4 / \mathrm{kg}$ qdX5) were given. CT scanning of the chest showed mild pneumonia, so antibiotics were administered appropriately.

After 8 days of treatment, the cell and protein aberrations in CSF improved, but the patient remained

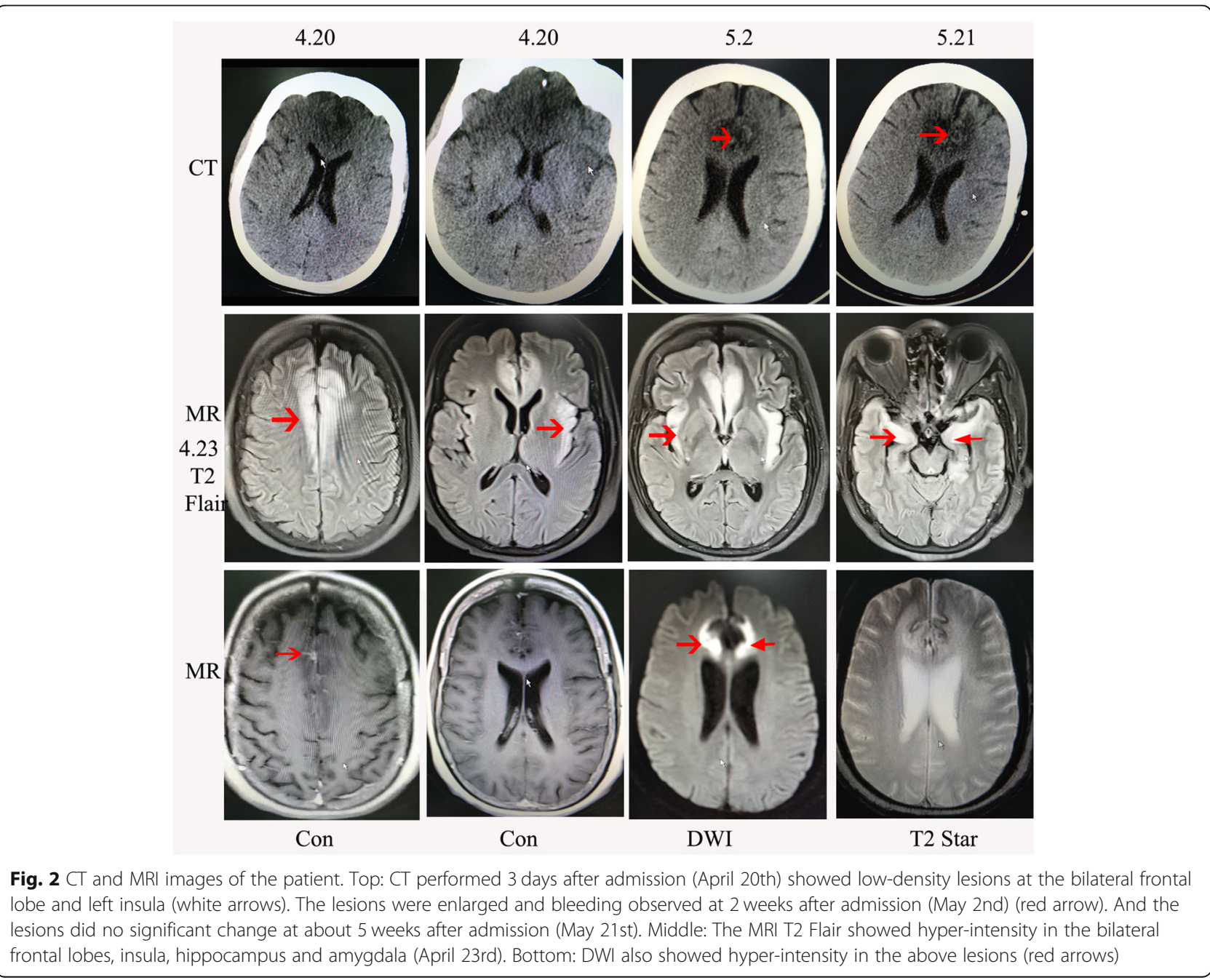


a VEEG presentation on the first day of admission(4.17,baseline)

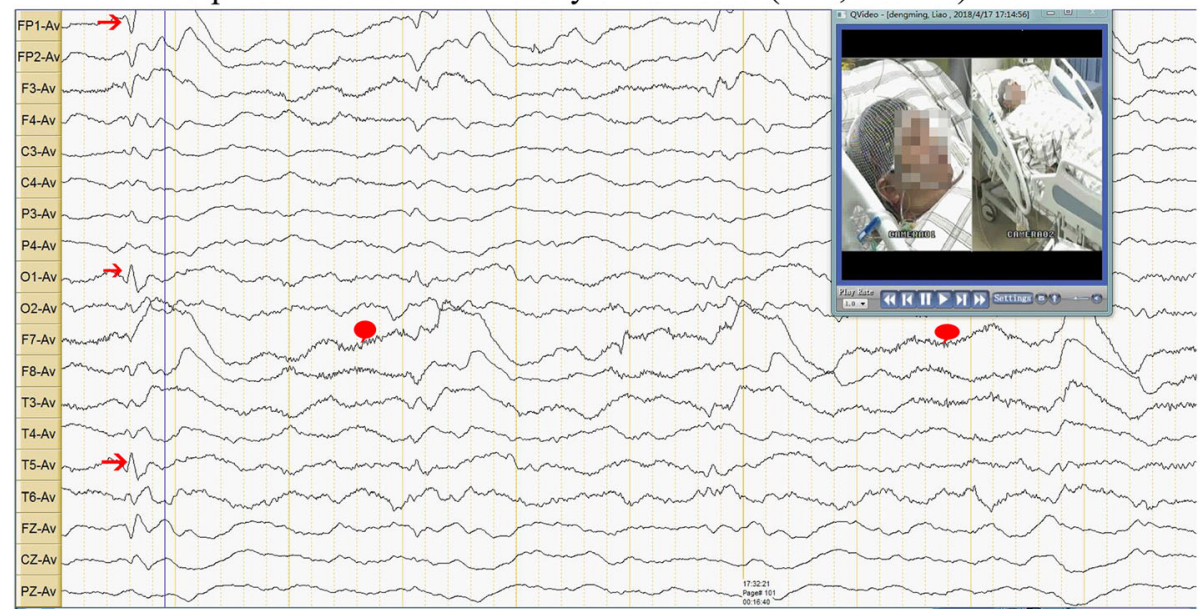

b VEEG presentation after diazepan intervention(4.18)

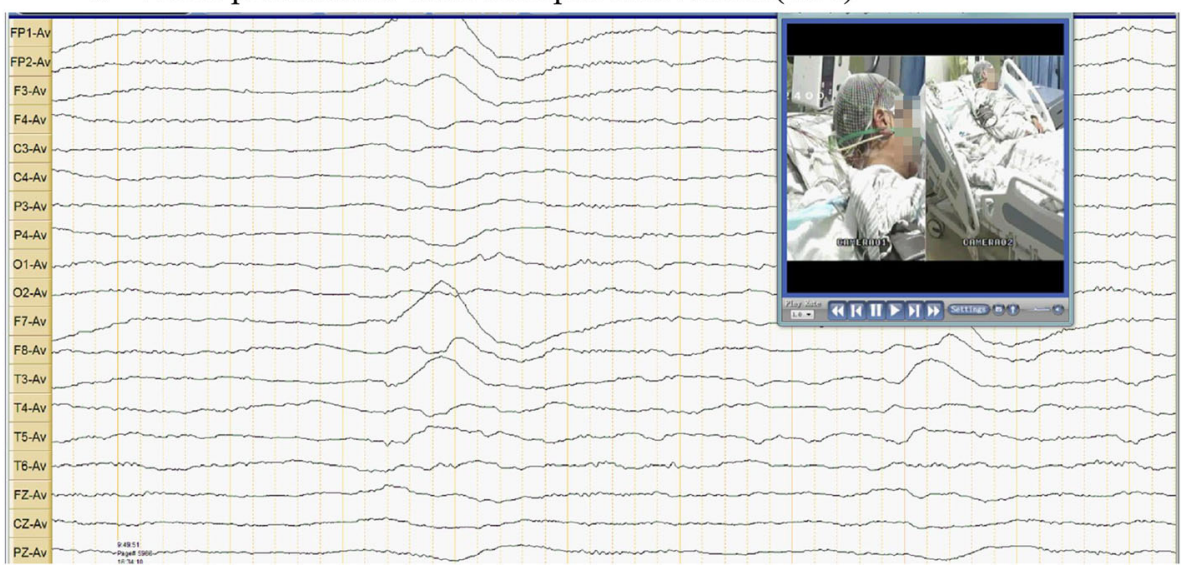

Fig. 3 Continuous video electroencephalography (CVEEG) presentation before and after diazepam intervention. a Video electroencephalography (VEEG) presentation on the day of admission. CVEEG showed diffuse slowing in the theta and delta range and periodic sharp-slow wave discharges (once/2-3S, as the red arrows showed) that correlated with the patient's rhythmic lip smacking movements (as the red dots showed). b VEEG presentation after diazepam intervention. The periodic discharges and rhythmic lip smacking movements were terminated after diazepam intervention

unresponsive to pain and VEEG still showed diffuse slowing in the delta range or a low voltage (Fig. 4). Two weeks after admission, she developed rhabdomyolysis with brown urine and upregulated creatine kinase (CK) (7 $000 \mathrm{IU} / \mathrm{L})$ and myosin (> 3 000) (Fig. 1). All medications including anti-epileptic drugs (AEDs), antibiotics and prednisone were temporarily discontinued. Treatment with intravenous fluids was performed to maintain above $6000 \mathrm{ml}$ urine production and sodium bicarbonate was administrated to alkaline urine. But the symptoms did not improve significantly.

Three weeks after admission, CT scanning showed lesion progression into punctate hemorrhage (Fig. 2). Cell and protein elevations re-emerged in the CSF, although the copies of HSV-1 DNA decreased significantly (40 copies). VEEG showed diffuse slowing in the delta range or even a low voltage (Fig. 3). These alterations were suggestive of an auto-immune condition, so the panel of autoimmune encephalitis was tested. One month after admission, a high-dose hormone therapy (prednisone $0.5 \mathrm{qdX} 3$; $0.24 \mathrm{qdX7)}$ ) was continued. One week later, blood levels of CK and myosin gradually decreased and the cell and protein levels in the CSF were also decreased. However, the patient was still in a state of unconsciousness and VEEG showed a low voltage.

Forty-two days after admission, the patient showed recurrent excessive sweating on the right forehead and the right pupil enlarged to $5 \mathrm{~cm}$ and was not reactive to light for about $8 \mathrm{~h}$. Brain CT rescanning showed no changes. VEEG showed paroxysmal slow waves, especially $0.5-1 \mathrm{~Hz}$ slow waves, alternating with low voltage (Fig. 4). These were considered as symptoms of autonomic seizures and AEDs 
a VEEG presentation 42days of admission(6.3)

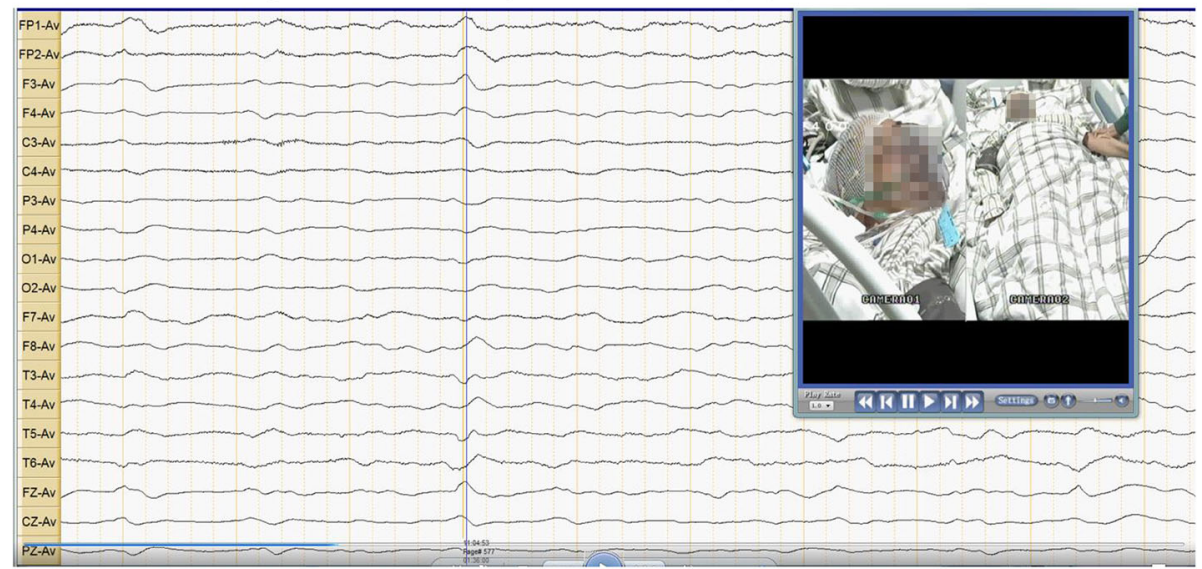

b VEEG presentation after 3 times plasma exchange(6.12)

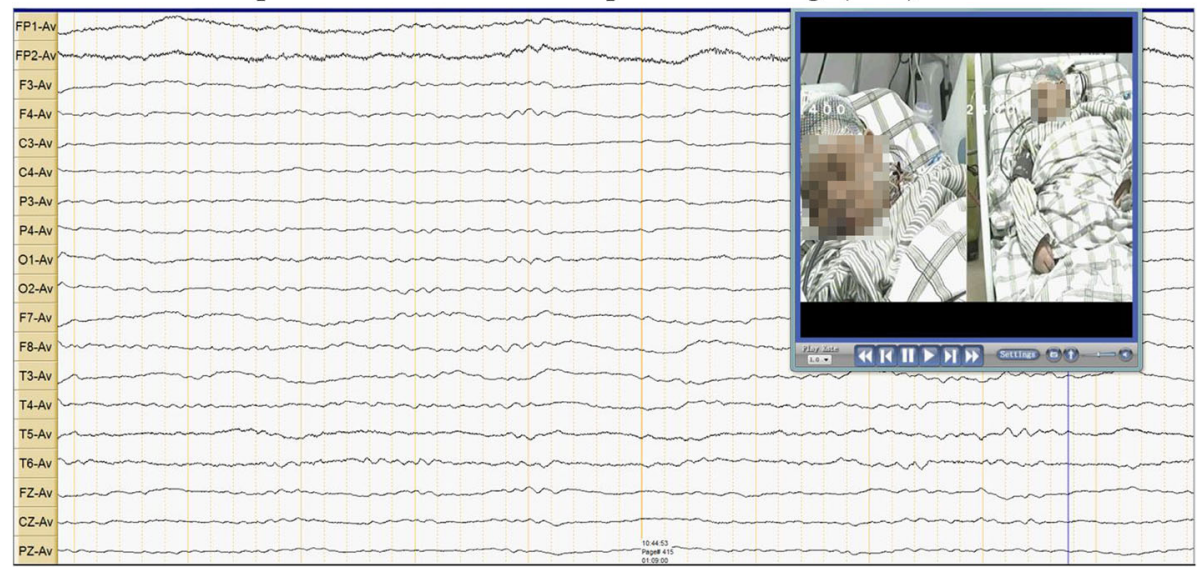

Fig. 4 Continuous VEEG presentation before and after plasma exchange. a Video electroencephalography (VEEG) presentation before plasma exchange 6 weeks after admission. The patient showed recurrent sweating profusely on the right forehead and enlargement of the right pupil. Continuous VEEG showed paroxysmal slow waves, especially $0.5-1 \mathrm{~Hz} / \mathrm{s}$ slow waves, alternating with low voltage with no reactivity. b VEEG presentation after plasma exchange. After 3 times of plasma exchange, VEEG showed alpha rhythm and the patient recovered consciousness

were adjusted to further include phenobarbitone. Although the panel of autoimmune encephalitis-related antibodies (both by ELISA and immunofluorescence) showed negative results, an immune response to severe virus infection was considered. Plasma exchange was performed. After 3 times of plasma exchange, the patient showed improvement of awareness and VEEG activity also improved (Fig. 5). The above phenomenon also evidenced the auto-immune responses after HSE. Six months after discharge, she can walk with the help of stick but her cognition was impaired with motor aphasia and poor memory.

\section{Literature review}

A literature search was made in the PubMed using keywords "EEG" and "HSE", and 58 literatures containing these keywords in abstract were displayed after search. Only 4 of them reported the outcome of HSE, so they were included in the review. Abnormal EEG is commonly seen in HSE. In 2007, Wen-Bin Hsieh et al. found that $79 \%$ of tested patients (40 cases) had abnormal EEG activity [9]. In addition, abnormal EEG activity was more prevalent in patients with HSV-1 encephalitis (11/12, 92\%) than in those with HSV-2 (15/21, 71\%). In the review by Tarun D. Singh et al., the abnormality of EEG in HSV-2 encephalitis $(8 / 9,88.9 \%)$ was higher than that in HSV-1 (26/33, 78.8\%). In a recent study, 223 out of 245 (91\%) HSE patients had abnormal EEG activity [10]. These findings consistently showed that the abnormal EEG activity is common in HSE patients.

The application of EEG in the diagnosis of HSE was started in as early as 1970 [4-6]. In 1988, Lai and Gragasin analyzed the role of EEG in the diagnosis of HSE [7]. EEG is more sensitive than other examinations such as CT and CSF analysis, especially in neonates $(100 \%)[6,7]$. However, the abnormal EEG patterns are usually nonspecific. Lai et al. concluded that the EEG of HSE patients in the acute period show a variety of abnormalities and the appearance of a focal or lateralized EEG abnormality is 
a Right pupile (5mm), not reactiv reactive to light

b Left pupile $(2 \mathrm{~mm})$, reactive to the light
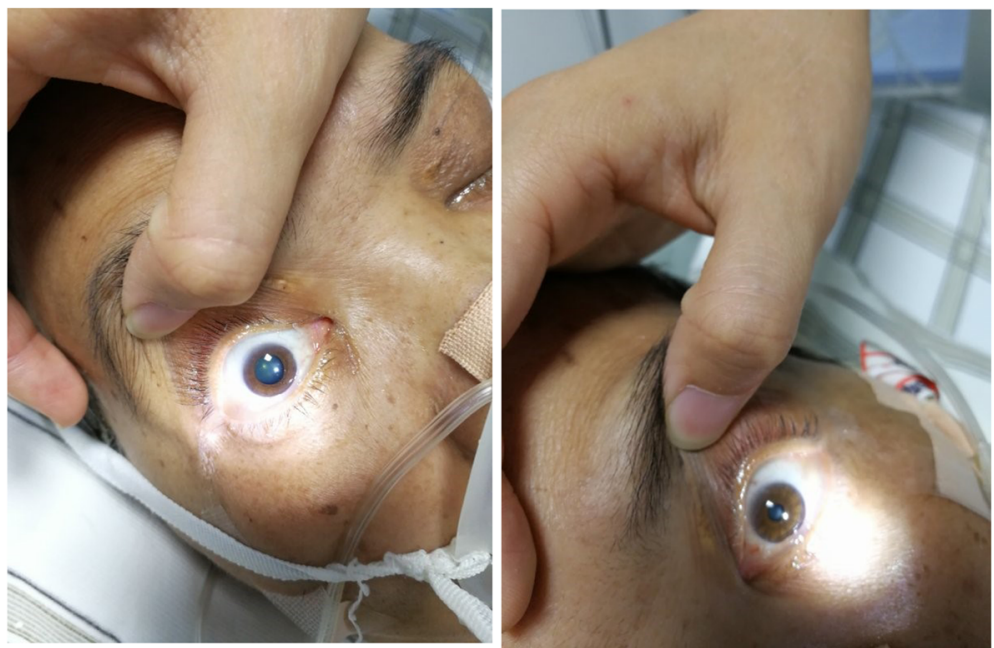

Fig. 5 The specific clinical presentation. The patient showed recurrent sweating profusely on the right forehead and the right pupil was enlarged to $5 \mathrm{~cm}$ with no reactivity to light for about $8 \mathrm{~h}$. The left pupil was normal

highly suspicious of HSE [7]. Cag et al. further propose that the EEG patterns in HSE are nonspecific, including diffuse high-amplitude slow waves, lateralized/localized slow waves, temporal lobe spike-and-wave activity, periodic lateralized epileptiform discharge (PLED) and other abnormalities [8]. Notably, PLEDs are often absent in the very early course. Temporal discharge (including PLEDs) spreading to the contralateral temporal lobe or frontal lobe is supportive for the diagnosis of HSE [3].

However, the occurrence of seizures has been reported less common than EEG abnormality. About $50-75 \%$ of patients with adult HSE were reported to have seizures during the acute or the subacute period [11-13]. Whitley revealed that in HSE, focal seizures are most frequent (65\%), followed by generalized seizures (23\%) [13]. The increase of seizures in HSE contributes to the lesions of the limbic system. During the acute period, one of the characteristics of EEG is the activity of spikes and slow waves arising from the unilateral temporal lobe $[7,10,14]$. The second type of EEG is the lateralizing epileptiform discharges $[3-5,15]$. During the subacute period, abnormal discharges spread to the contralateral temporal lobe or even bilateral hemispheres [3]. Meanwhile, status epilepticus (SE) may also be present in HSE, especially in the acute period. However, most of the findings were from case reports, rather than large-population studies. In 2008, Misra et al. reviewed SE in the central nervous system infections and found that 4 out of 14 patients with HSE (29\%) developed SE [16]. In fact, SE is under-diagnosed among NCSE patients without the help of CVEEG. Notably, epileptic nystagmus as the only symptom of NCSE has been reported in HSE [17]. Moreover, there is a lack of a consensus on the criteria for NCSE EEG. Particularly, the NCSE-correlated paroxysmal high-amplitude slow waves and PLED are often missed. Therefore, CVEEG is required in HSE.

Since EEG examination is a sensitive tool for the diagnosis of HSE, we wondered if it could be a biomarker for the outcome of HSE? This has been discussed in several reviews but conclusions are contradictory. In as early as 1988, Lai and Gragasin considered that EEG findings in either the acute stage or the long-term follow-up did not predict the chance of survival or severity of disability, and EEG changes appeared to lag behind the clinical changes [7]. They proposed that EEG activity could return to normal in both adults and neonates when the acute stage is over [7]. In 2012, Sellner J et al. reviewed that not only seizures were not associated with high mortality, but also the abnormal EEG frequency in HSE patients did not correlate well with clinical recovery [3]. However, there are also studies reporting that seizures especially refractory status epilepticus (RSE) were significantly related to a poor 3-month outcome. Moreover, there are several EEG parameters associated with a poor outcome of HSE (Table 1), which are (1) the frequency of slow wave; (2) the distribution of slow waves; (3) special waves: PLED, bilateral PLEDs, RSE, and burst suppression; (4) reactivity to stimulus (non-reactivity); and (5) background of EEG (lack of posterior dominant rhythm [PDR] or sleep architecture).

\section{Discussion}

HSV PCR in the CSF has become the gold standard for the diagnosis of HSE due to its high sensitivity and specificity [18]. However, sometimes it may yield false negative results [19]. Here we found that EEG is more sensitive than other examinations in the context of HSE. The EEG abnormality 
Table 1 Various EEG patterns associated with a poor outcome in HSE

\begin{tabular}{|c|c|c|}
\hline EEG patterns & Outcome & Reference \\
\hline \multicolumn{3}{|l|}{ Frequency of slow wave: } \\
\hline Delta activity & Poor & Baten A [14], Kim YS [22] \\
\hline \multicolumn{3}{|l|}{ Distribution of slow wave: } \\
\hline Spread of delta activity & Poor & Baten A [14], Kim YS [22] \\
\hline Diffuse high-amplitude slow waves & Poor & Sili U [23] \\
\hline \multicolumn{3}{|l|}{ Reactivity to stimulus: } \\
\hline No reactivity & Poor & Baten A [14], Kim YS [22] \\
\hline No alpha and theta reactivity & Poor & Sili U [23] \\
\hline \multicolumn{3}{|l|}{ Special waves: } \\
\hline Burst suppression & Poor & Singh TD [24] \\
\hline Refractory status epilepticus & Poor & Baten A [14] \\
\hline Alpha and theta coma & Poor & Kim YS [22] \\
\hline PLED or biPLEDs & Poor & Sili U [23] \\
\hline \multicolumn{3}{|l|}{ Background of EEG: } \\
\hline Absence of PDR & Poor & Singh TD [24] \\
\hline Absence of sleep architecture & Poor & \\
\hline
\end{tabular}

in our case showed dynamic progression, which in the acute period was dominated by lateral discharges especially in the temporal lobe, and in the subacute period spread throughout the whole hemisphere. This pattern of EEG evolution supports the diagnosis of HSE.

CVEEG is an important tool to identify NCSE. In the acute period, the patient showed periodic discharges in correlation with her rhythmic lip smacking movements and responded to diazepam intervention, which was considered to be NCSE according to the Salzburg Consensus Criteria for NCSE [20]. In addition, 6 weeks after admission, the patient presented with paroxysmal eye gaze during synchronous delta rhythm, which was also suggestive of NCSE. It has been reported that NCSE is common in patients with coma [21] and immediate AED treatment is key to the outcome of the disease. Moreover, the patient also showed recurrent sweating profusely on the right forehead and the right pupil enlarged to $5 \mathrm{~cm}$ with no response to light for about $8 \mathrm{~h}$. CVEEG showed paroxysmal slow waves especially $0.5-1 \mathrm{~Hz}$ slow waves, alternating with low voltage, which could be considered as autonomic seizures.

Abnormal EEG activity is common in HSE. EEG abnormality patterns that are related to poor outcome of HSE patients include: (1) slower waves; (2) wider extension of slow waves; (3) emergence of special waves, such as PLED, bilateral PLEDs, RSE and burst suppression; (4) no reactivity to stimulus in coma; and (5) a lack of PDR or sleep architecture. In this report, the patient at a chronic period showed severe cortical lesions with diffuse delta rhythm or low voltage and did not respond to stimulus, which predicted a poor outcome or a long time needed for recover. According to the CVEEG activity, antivirus drugs were used for over 1 month combined with a continuous high-dose prednisone therapy, and plasma exchange was performed 2 months after admission. Therefore, CVEEG is a good tool to investigate the progression of HSE.

In conclusion, the patterns of EEG abnormality in HSE are not specific, but some are related to poor outcomes. Besides, the CVEEG can not only be used to identify NCSE but is also an important tool for monitoring the progression of HSE.

\section{Informed consent \\ Written informed consent for publication of the patient's clinical details and/or clinical images was obtained from the husband of the patient.}

\section{Abbreviations \\ CSF: Cerebrospinal fluid; CK: Creatine kinase; CT: Computed tomography; HSE: Herpes simplex encephalitis; HSV-1: Herpes simplex infection-1; HSV- 2: Herpes simplex infection-2; MRI: Magnetic resonance imaging; NCSE: Non- convulsive status epilepticus; PLED: Periodic lateralized epileptiform discharge; PDR: Posterior dominant rhythm; PCR: Polymerase chain reaction; RSE: Refractory status epilepticus; VEEG: Video electroencephalography}

\section{Acknowledgements}

We thank the patient and her family for coordination and all medical staff in the neurological intensive care unit of Fujian Medical University Union Hospital for providing medical care for the patient.

\section{Authors' contributions}

WH. Lin and SG. C contributed equally to this work and they are co-first authors. HP. Huang is the corresponding author. HB. Lin is contributed to collect the data and CY. Liu is contributed to manage the patient. The authors read and approved the final manuscript.

\section{Funding}

This study was supported by the General Project of National Natural Science Foundation of China (Grant No. 81901311)

\section{Availability of data and materials}

Please contact authors for data requests.

\section{Ethics approval and consent to participate}

This article is a retrospective report without affecting the treatment. This report was approved by Fujian Medical University Union Hospital Ethics Committee.

\section{Consent for publication}

All authors agree to publish the study. Written informed consent for publication of the patient's clinical details and/or clinical images was obtained from the husband of the patient.

\section{Competing interests}

The authors declared no commercial or financial conflict of interest.

\section{Author details}

${ }^{1}$ Intensive Care Unit, Department of Neurology, Fujian Medical University Union Hospital, Fuzhou 350001, China. ${ }^{2}$ Department of Neurology, Fujian Medical University Union Hospital, Fuzhou 350001, China. ${ }^{3}$ Department of Geriatrics, Fujian Medical University Union Hospital, Fujian Key Laboratory of Molecular Neurology, Fuzhou 350001, China. 
Received: 10 November 2019 Accepted: 12 May 2020

Published online: 29 July 2020

\section{References}

1. Croll BJ, Dillon ZM, Weaver KR, Greenberg MR. Mri diagnosis of herpes simplex encephalitis in an elderly man with nonspecific symptoms. Radiology Case Rep. 2017;12:159-60.

2. Jakob NJ, Lenhard T, Schnitzler P, Rohde S, Ringleb PA, Steiner T, et al. Herpes simplex virus encephalitis despite normal cell count in the cerebrospinal fluid. Crit Care Med. 2012;40:1304-8.

3. Sellner J, Trinka E. Seizures and epilepsy in herpes simplex virus encephalitis: current concepts and future directions of pathogenesis and management. J Neurol. 2012;259:2019-30.

4. Upton A, Gumpert J. Electroencephalography in diagnosis of herpessimplex encephalitis. Lancet. 1970;1:650-2.

5. Upton A, Gumpert J. Electroencephalography in the early diagnosis of herpes simplex encephalitis. Revue d'electroencephalographie et de neurophysiologie clinique. 1971;1:81-3.

6. Brodtkorb E, Lindqvist $\mathrm{M}$, Jonsson $\mathrm{M}$, Gustafsson A. Diagnosis of herpes simplex encephalitis. A comparison between electroencephalography and computed tomography findings. Acta Neurol Scand. 1982;66:462-71.

7. Lai CW, Gragasin ME. Electroencephalography in herpes simplex encephalitis. J Clin Neurophysiol. 1988;5:87-103.

8. Cag Y, Erdem H, Leib S, Defres S, Kaya S, Larsen L, et al. Managing atypical and typical herpetic central nervous system infections: results of a multinational study. Clin Microbiol Infect. 2016;22:568 e569-17.

9. Hsieh WB, Chiu NC, Hu KC, Ho CS, Huang FY. Outcome of herpes simplex encephalitis in children. J Microbiol Immunol Infect= Wei mian yu gan ran za zhi. 2007:40:34-8.

10. Erdem H, Cag Y. Managing atypical and typical herpetic central nervous system infections: results of a multinational study - authors' reply. Clin Microbiol Infect. 2017;23:421-2.

11. McGrath N, Anderson NE, Croxson MC, Powell KF. Herpes simplex encephalitis treated with acyclovir: diagnosis and long term outcome. J Neurol Neurosurg Psychiatry. 1997:63:321-6.

12. Misra UK, Kalita J. Seizures in encephalitis: predictors and outcome. Seizure. 2009:18:583-7.

13. Whitley RJ. Herpes simplex encephalitis: adolescents and adults. Antivira Res. 2006;71:141-8.

14. Baten A, Desai M, Melo-Bicchi M, Gutierrez C. Continuous electroencephalogram as a biomarker of disease progression and severity in herpes simplex virus-1 encephalitis. Clin EEG Neurosci. 2019;50:361-5.

15. Smith JB, Westmoreland BF, Reagan TJ, Sandok BA. A distinctive clinical eeg profile in herpes simplex encephalitis. Mayo Clin Proc. 1975;50:469-74.

16. Misra UK, Kalita J, Nair PP. Status epilepticus in central nervous system infections: an experience from a developing country. Am J Med. 2008;121:618-23.

17. Lee JH, Nam DH, Oh SY, Shin BS, Seo MW, Jeong SK, et al. Nonconvulsive status epilepticus presenting as epileptic nystagmus in a patient with herpes encephalitis. J Neuro-Ophthalmol. 2012;32:249-51.

18. Denes E, Labach C, Durox H, Adoukonou T, Weinbreck P, Magy L, et al. Intrathecal synthesis of specific antibodies as a marker of herpes simplex encephalitis in patients with negative pcr. Swiss Med Wkly. 2010;140:w13107.

19. Mendez AA, Bosco A, Abdel-Wahed L, Palmer K, Jones KA, Killoran A. A fatal case of herpes simplex encephalitis with two false-negative polymerase chain reactions. Case Rep Neurol. 2018;10:217-22.

20. Leitinger M, Beniczky S, Rohracher A, Gardella E, Kalss G, Qerama E, et al. Salzburg consensus criteria for non-convulsive status epilepticus--approach to clinical application. Epilepsy Behavior. 2015;49:158-63.

21. Trinka $\mathrm{E}$, Leitinger $\mathrm{M}$. Which eeg patterns in coma are nonconvulsive status epilepticus? Epilepsy Behavior. 2015;49:203-22.

22. Kim YS, Jung KH, Lee ST, Kang BS, Yeom JS, Moon J, et al. Prognostic value of initial standard eeg and mri in patients with herpes simplex encephalitis. J Clin Neurol. 2016:12:224-9.

23. Sili U, Kaya A, Mert A, Group HSVES. Herpes simplex virus encephalitis: clinical manifestations, diagnosis and outcome in 106 adult patients. J Clin Virol. 2014;60:112-8.

24. Singh TD, Fugate JE, Hocker S, Wijdicks EFM, Aksamit AJ Jr, Rabinstein AA. Predictors of outcome in hsv encephalitis. J Neurol. 2016;263:277-89.

Ready to submit your research? Choose BMC and benefit from:

- fast, convenient online submission

- thorough peer review by experienced researchers in your field

- rapid publication on acceptance

- support for research data, including large and complex data types

- gold Open Access which fosters wider collaboration and increased citations

- maximum visibility for your research: over $100 \mathrm{M}$ website views per year

At BMC, research is always in progress.

Learn more biomedcentral.com/submissions 